\title{
Planform geometry of peat meanders
}

\author{
W.M. Appels* \\ Hydrology and Quantitative Water Management Group, Department of Environmental Sciences, Wageningen \\ University, Wageningen, The Netherlands
}

\author{
A.J.F. Hoitink \\ Hydrology and Quantitative Water Management Group, Department of Environmental Sciences, Wageningen \\ University, Wageningen, The Netherlands \\ Institute for Marine and Atmospheric Research Utrecht, Department of Physical Geography, \\ Utrecht University, Utrecht, The Netherlands
}

D.H. Hoekman

Soil Physics, Ecohydrology, and Ground Water Management Group, Department of Environmental Sciences, Wageningen University, Wageningen, The Netherlands

\begin{abstract}
Rivers that drain the pristine, isolated peat areas in Kalimantan and Sumatra feature very distinct meandering patterns, which were observed from satellite RADAR images. This research quantifies the planform differences between peat rivers and alluvial rivers in the same geographical region. A geometrical analysis was applied to three rivers in Central Kalimantan and South East Sumatra. Geometric parameters were defined and measured and multivariate statistics were applied. The measured parameters and their statistical properties were grouped based on a factor analysis by Howard and Hemberger (1991). It is concluded that peat rivers are characterized by a high kurtosis and a high skewness of their curvature series, and comparatively low values of the half-sinuosity and total sinuosity parameters. In the adopted approach subjective decisions need to be made regarding the definition and selection of individual meanders. The curvature series of a river can do without subjective definitions of parameters.
\end{abstract}

\section{INTRODUCTION}

Although meandering is defined as a single class of river patterns, many distinctions can be made between river meanders. Different rivers may display different patterns, or the meandering pattern can change along the river channel. RADAR images of two tropical peat areas in Sumatra and Kalimantan, Indonesia, show very different patterns of meandering rivers within a region. These differences occur between the rivers that flow through peat domes and rivers that flow in alluvial subsoil. Rivers in peatlands are poorly studied, and are therefore the object of study herein.

Peatlands in Indonesia developed over the past 5.000 years in flat coastal alluvial plains (Silvius, 2005). As the lowland plains expanded seawards, several desalting succession stages and accumulation of

* Now at the Soil Physics, Ecohydrology, and Ground Water Management Group, Department of Environmental Sciences, Wageningen University, Wageningen, the Netherlands organic material facilitated the transformation of mangrove forest to a forested, but waterlogged ecosystem. The peatlands that are found in tropical, rainy climate zones consist mainly of trees, in contrast to peatlands in temperate climate zones that mainly consist of mosses (Wikramanyake et al., 2002). Due to permanent water logging, the accumulation rate of organic material is higher than the decomposition rate of the material. When trunks, branches, roots, and leaves accumulate, they form domes with reported heights from 1 to $24 \mathrm{~m}$ (Silvius, 2005).

The topography of the mineral subsoil usually drops from an alluvial river or the sea coast, giving the peat domes a lens-shaped cross-section (Fig. 1) (Ritzema $\&$ Wösten, 2002). The vegetation on the slopes and the top of the domes is fed exclusively by rain (ombrogenous peat). The domes are not convex, but flatten out somewhat at the top, as trees at the top reach a smaller height than the trees growing at the slopes.

The drainage of peat forests is very diffuse. Runoff flows occur through and over the upper topsoil. Less 
than three percent of the rainfall infiltrates in the mineral subsoil and contributes to the groundwater flow (Silvius, 2005). In the peat domes the water table is located at or just below the dome surface. There is no capillary rise of water in a peat dome as its pores are too large. Local concentration of runoff washes away parts of the peat, resulting in river formation. The riverbeds of these peat rivers are very irregular, consisting of large organic material. The river water is black, due to organic acids, but the rivers do not contain sediment.

In general, peat forests do not have the biodiversity that is found in lowland rain forests. However, while these forests are being destroyed, peat forests become a key habitat for endangered species such as the orang-utan (Wikramanayake et al., 2002). Due to increasing population and economic pressure, peat forests in Indonesia are opened for e.g. rice and oil palm cultivation. When the peat domes are drained they collapse, as their water content is over 85 percent. The organic material oxidize, releasing large

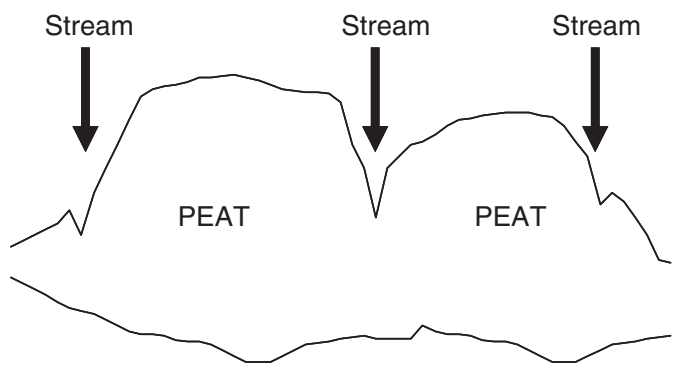

MINERAL SUBSOIL quantities of $\mathrm{CO}_{2}$ into the atmosphere. Forest fires, initiated to prepare logged areas for agriculture, form another threat for the peat areas. The disappearance of peat domes may lead to a loss of fresh water in coastal areas and a higher salt intrusion due to the decrease of fresh water pressure (Silvius, 2005).

The rivers under study in this research are found in the Berbak National Park, Jambi Province, Sumatra and in Mawas Peat Reserve, Central Kalimantan, Kalimantan (Fig. 2). The river Mantangai drains two large peat domes in Mawas Peat Reserve. It is about $60 \mathrm{~km}$ long and flows through peat debris until its confluence with the river Kapuas. It is approximately two to three meters deep and lies on ten meters of peat. The river Kapuas is a large river draining the central mountain range of Kalimantan. It is embedded in alluvial floodplains and has a width up to $400 \mathrm{~m}$. A downstream trajectory of the river borders Mawas Peat Reserve. River Air Hitam Laut and its tributaries drain Berbak National Park. The larger part of the river network flows through peat debris, like river Mantangai, further downstream the river is embedded in alluvial sediments. The peat forest in both areas suffered severely from forest fires the nineties.

The aim of this research is to come to an objective quantitative description of the differences of the meandering patterns of peat rivers and alluvial rivers in these peat forests.

\section{METHOD}

The RADAR images were obtained from the Japanese Earth Resources Satellite JERS-1. High resolution images of this satellite have a pixel width of $12.5 \mathrm{~m}$ and a pixel resolution of $30 \mathrm{~m}$. Both the images of Mawas

Figure 1. Schematic cross-section of a peat dome.

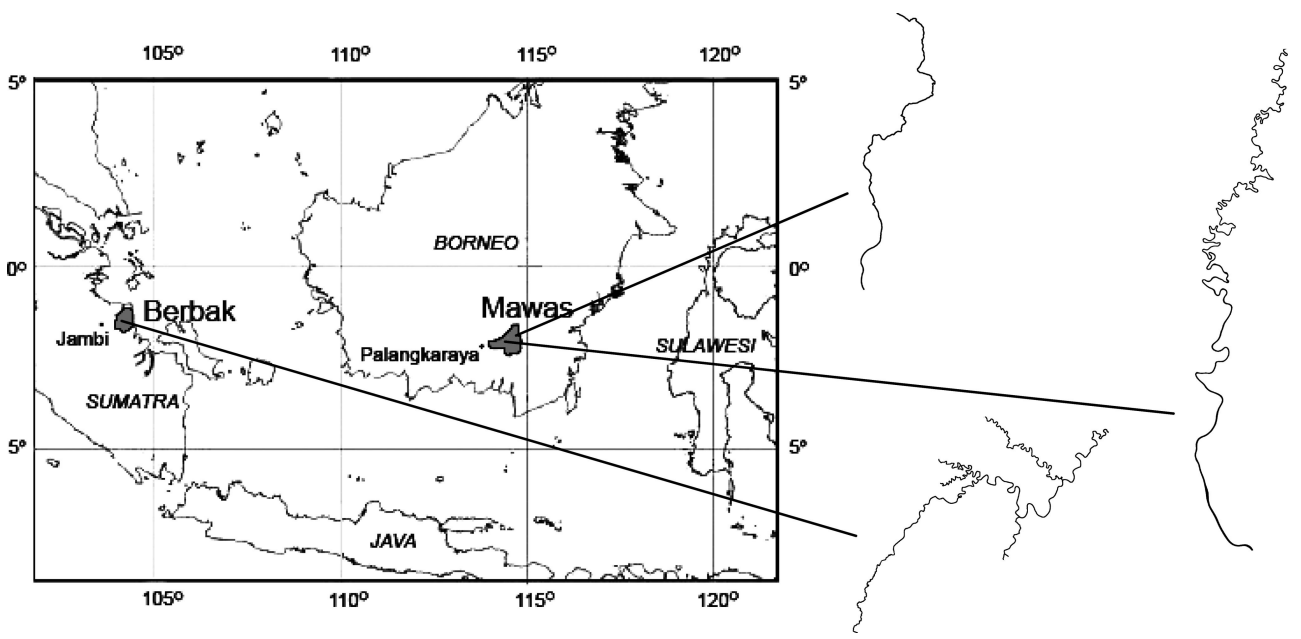

Figure 2. Location of Berbak National Park and Mawas peat reserve (after Hajnsek et al., 2005). 
Peat Reserve and Berbak National Park were averaged, but otherwise unprocessed, grey value images. The three rivers (Fig. 3) consisted of eight reaches, five of which were alluvial, three of which were peat reaches. The rivers were selected from the original images with standard imaging software.

The Matlab contour algorithm was used to draw the river banks. From the tangent of each point of the bank a cross-section of the river was drawn. The midpoint of each cross-section was saved. This operation was performed from both the left and the right bank. The resulting two datasets were averaged to one approximation of the river centerline. A Savitzky-Golay filter (Savitzky \& Golay, 1964) was applied to the $x$ and $y$ coordinates of the approximated centerline.

This filter replaces each coordinate by a local average of neighboring points in a moving window according to:

$x_{i}^{\text {filtered }}=\frac{1}{2 k+1} \sum_{j=-k}^{k} g_{i+j} x_{i+j}$ $y_{i}^{\text {filtered }}=\frac{1}{2 k+1} \sum_{j=-k}^{k} g_{i+j} y_{i+j}$

where $g_{j}$ are the averaging coefficients and $2 k+1$ is the filter window size. For the studied rivers good results were obtained by applying the filter twice. First it was applied to every third point of the centerline in a 15 point filter window and a fifth order polynomial. The second time all filtered points were inserted in the filter with window size nine and a fifth order polynomial. The resulting doublefiltered centerline was interpolated with a cubic spline interpolation.

In the river reaches, the basic unit for describing the geometry was a half-meander (coinciding with a river reach in between two consecutive inflection points). An inflection points is defined as a location where the curvature is equal to zero. The curvature $c$ was determined according to a three-point algorithm on the
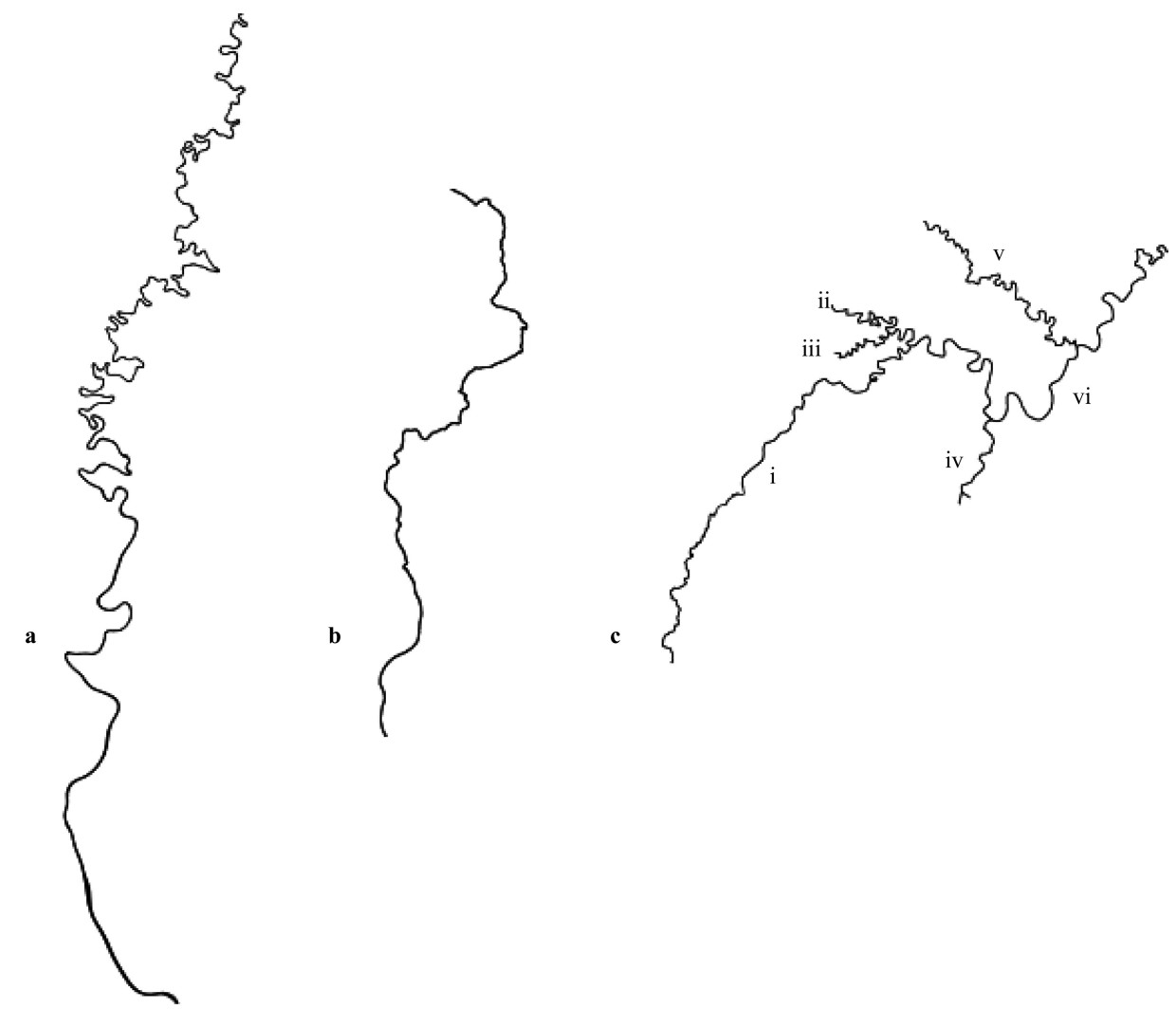

Figure 3. The planimetry of rivers (a) Kapuas (alluvial); (b) Mantangai (peat); (c) Air Hitam Laut. The tributaries of the Air Hitam Laut network are numbered. Reaches i and iv are peat reaches, the reaches ii, iii, and vi are alluvial reaches. 

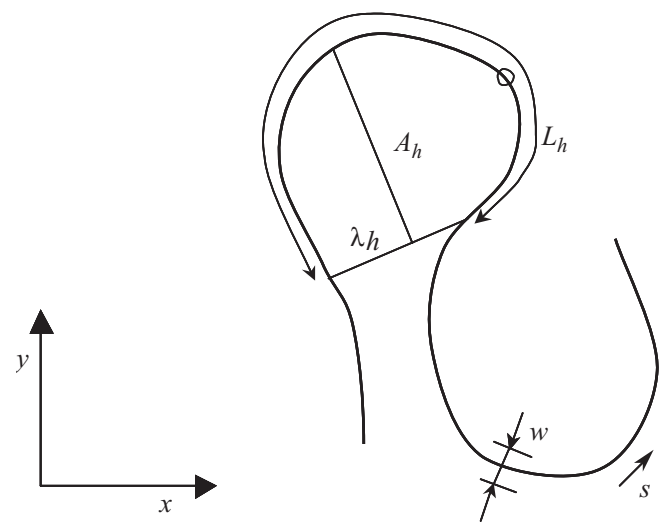

Figure 4. Half-meander geometry. Definition of river width $(w)$, amplitude $\left(A_{h}\right)$, channel length $\left(L_{h}\right)$, and wavelength $\left(\lambda_{h}\right)$. The circle indicates the point of maximum curvature. The channel axis $(s)$ is positive in downstream direction.

discretised centerline with equidistant discretisation points according to:

$c=-\frac{\partial \theta}{\partial s} \cong-\frac{(\arcsin \alpha \wedge \beta)}{|\alpha \| \beta| \Delta s} \cong \frac{\alpha_{y} \beta_{x}-\alpha_{x} \beta_{y}}{\Delta s^{3}}$

where $\alpha$ and $\beta$ are the vectors from point $i-1$ to $i$ and point $i$ to point $i+1$ respectively. In Equation $3, \Delta \mathrm{s}$ is the interpolation distance (Camporeale et al., 2005). Following this definition, the curvature is positive in meanders curving clockwise downstream and equal to zero at the inflection points.

The geometrical characteristics for every halfmeander are visualized in Figure 4. The asymmetry of each half-meander, denoted by $\Theta$, can be defined as the difference between upstream and downstream channel length from the point of maximum curvature to the neighbouring inflection points:

$\Theta=\left(L_{u}-L_{d}\right) / L_{h}$

The extent of curvature of every half-meander is described by the sinuosity $\mu_{h}$.

$\mu_{h}=L_{h} / \lambda_{h}$

The sinuosity was not only determined per halfmeander but, analogous to Howard \& Hemberger (1991), also for other compositions of channel length and wavelength. The half-sinuosity $\mu_{H}$ totals the halfmeander lengths and wavelengths before determining the ratio of the two.

$\mu_{H}=\sum_{i=1}^{n} L_{h, i} / \sum_{j=1}^{n} \lambda_{h, j}$
The whole-meander sinuosity $\mu_{W}$ is the ratio of the sum of half-meander wavelengths to the sum of wholemeander wavelengths $\lambda_{w}$.

$\mu_{W}=\sum_{i=1}^{n} \lambda_{h, i} / \sum_{j=1}^{l} \lambda_{w, j}$

The residual sinuosity $\mu_{R}$ is the ratio of the sum of whole-meander wavelength $\lambda_{w}$ divided by the distance between the first and the last inflection point of the reach, measured along a straight line $(D)$.

$\mu_{R}=\sum_{i=1}^{l} \lambda_{w, i} / D$

The total sinuosity is the total channel length divided by $D$.

$\mu_{T}=\sum_{i=1}^{n} L_{h, i} / D$

Howard \& Hemberger (1991) applied a factor analysis to a set of 28 variables determined in a sample of 83 model streams and a sample of 57 natural meandering rivers to be able to differentiate between the two samples. The factor axes they obtained for the sample of natural rivers was used to scale the peat and alluvial rivers under study. The scaling did not only require the determination of the geometrical parameters mentioned previously, but in subsets according to half-meander length as well.

The first subset consisted of half-meanders with lengths between the 30th percentile and median halfmeander length of the river set, the second subset of half-meanders with lengths between the 60th and 90th percentile half-meander length of the river set. The ratio of these subset values was included in the scaling procedure. Two frequencies were determined. Frequency $R_{m}$ compares the amount of medium-sized half-meanders (four to ten times the river width) to the total amount of half-meanders according to:

$R_{m}=\left(N_{4-6}+N_{7-10}\right) / N_{t}$

Frequency $R_{T}$ compares the amount of small halfmeanders (one to three times the river width) to the amount of large half-meanders ( 11 to 60 times the river width) according to:

$$
R_{T}=\left(N_{1}+N_{2-3}\right) /\left(N_{11-20}+N_{21-35}+N_{36-60}\right)
$$

\section{RESULTS}

Figure 5 synthesizes of the results of the analysis. The typical geometry of the alluvial river reaches 

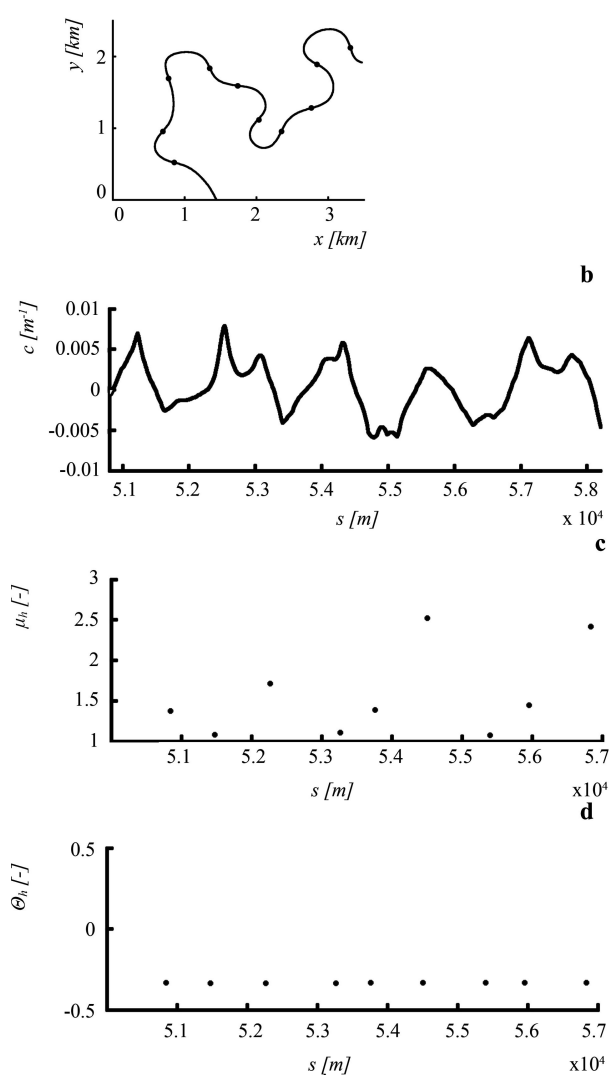
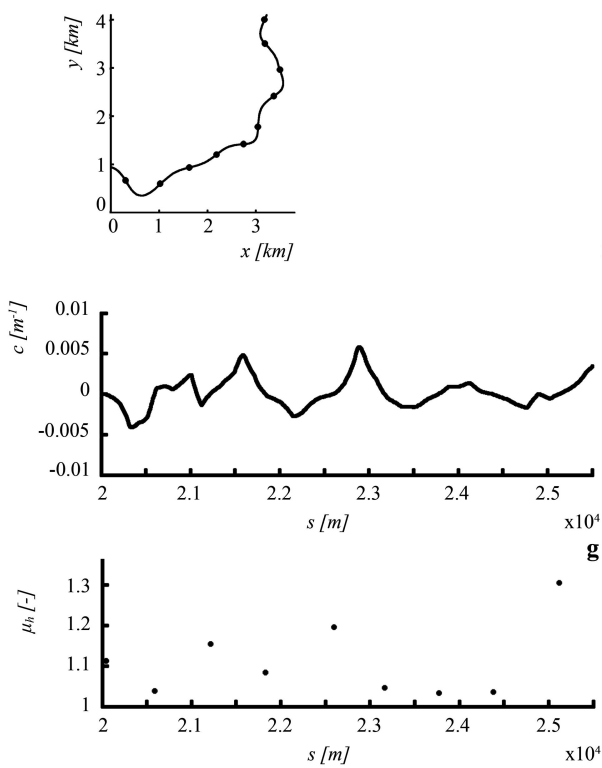

$\mathbf{h}$

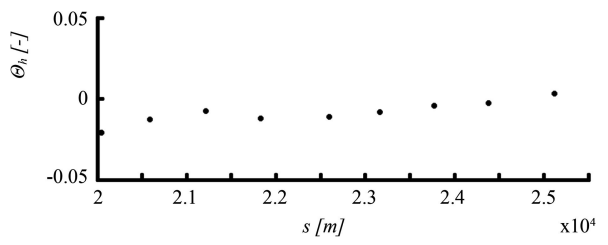

Figure 5. (a) typical channel axis configuration Air Hitam Laut, corresponding (b) curvature, (c) half-meander sinuosity, (d) asymmetry. (e) Typical channel axis configuration Mantangai, corresponding (f) curvature, (g) half-meander sinuosity, (h) asymmetry.

(illustrated in Figure 5a) is characterized by a combination of long, sinuous $\left(\mu_{h}>1.5\right)$, large-amplitude bends interspersed with shorter half-meanders of lower sinuosity $\left(\mu_{h}<1.5\right)$ (Fig. 5c). All half-meanders are upstream skewed (Fig. 5d), the degree of asymmetry being quite constant along the entire pattern. The curvature (Fig. 5b) has equal peaks to both sides of the stream interspersed with low curvature bends.

In the geometry of the peat rivers (a typical pattern is presented in Figure 5e) short half-meanders have a higher curvature than long half-meanders. The short half-meanders have the highest sinuosities (Fig. 5g), yet $\mu_{h}$ remains smaller than 1.5. The larger part of the pattern consists of long, nearly straight half-meanders. Consequently, the curvature series (Fig. 5f) contains relatively few large peaks.

In general, the peaks from the short half-meanders mark the end and beginning of a meander in the lowfrequent meandering pattern of the river. The degree of asymmetry of the bends, all of which are upstream
Table 1. Sinuosity parameters.

\begin{tabular}{llllll}
\hline Sinuosity & $\mu_{h(a v)}$ & $\mu_{H}$ & $\mu_{T}$ & $\mu_{W}$ & $\mu_{R}$ \\
\hline Peat rivers & 1.2 & 1.2 & 1.4 & 1.0 & 1.2 \\
Alluvial rivers & 1.6 & 1.5 & 2.2 & 1.1 & 1.3 \\
\hline
\end{tabular}

skewed, (Fig. 5h) is constant over the entire pattern, similar to the asymmetry of the alluvial reaches, but a factor 10 smaller in size.

For both the river types, the asymmetry of the individual half-meanders is not very pronounced (compare Figures 5d, 5h).

In general, peat rivers feature lower values for the sinuosity parameters than alluvial rivers (Table 1 ).

The averaged half-meander sinuosity, the half sinuosity and the total sinuosity diverge more than the whole sinuosity and the residual sinuosity.

Considering a symmetrical meandering pattern with no superposition of one meandering pattern 
to another, the first three sinuosity parameters will be equal, resulting in unit values for the latter two sinuosity parameters. Skewing of the individual halfmeanders will increase the value of the whole sinuosity, whereas a curved valley axis will result in a higher residual sinuosity.

The curvature series in Figure 6 have not been width-normalized due to the low image resolution. The range of curvature values is larger for the alluvial rivers than for the peat rivers, which can also directly be seen in the planform of the rivers (Fig. 3). The curvature series of Kapuas, Mantangai, and reaches $i$ and vi from Air Hitam Laut (Figs. 6a, 6e, 6f, 6c respectively) all show trends in their curvature development along the $s$-axis. In reach Air Hitam Laut vi this is caused by the occurrence of compound meanders in the downstream section of the river reach. The planform of the other rivers changes in the downstream direction to a pattern of larger, bends with a weaker curvature. The curvature pattern of reach ii of Air Hitam Laut (Fig. 6b) displays a typical alluvial form of compound meandering. The compound meanders consist of two strongly curved half-meanders to one side of the stream and a halfmeander featuring weaker curvature, connecting the
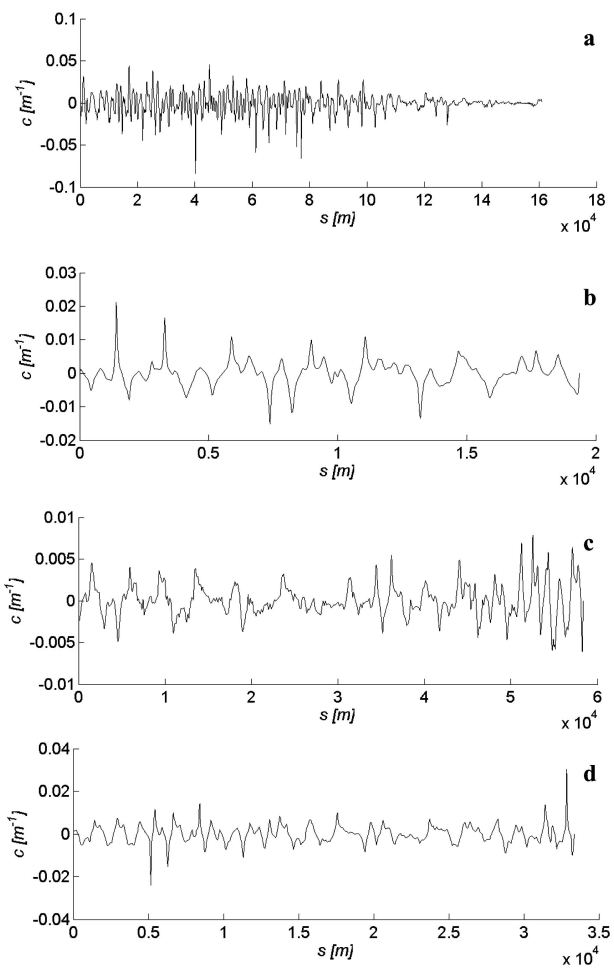

two. In accordance with the direct observations from the river planform (Fig. 3), the pattern of the curvature series is more regular for the alluvial river reaches than for the peat rivers. This can be observed in Figures $6 \mathrm{~g}$ and $6 \mathrm{~h}$.

The statistics of the curvature presented in Table 2 quantify the differences of the geometrical patterns.

The values of skewness indicate that the right tail of the distribution of curvature values is longer than the left tail for both river types and that peat rivers have a longer tail than alluvial rivers. The higher kurtosis values for the peat rivers indicate that more of the variation of their curvature series is due to infrequent, extreme deviations. These deviations are the short,

Table 2. Curvature statistics.

\begin{tabular}{lll}
\hline Curvature & $\gamma_{1}$ & $\gamma_{2}$ \\
\hline Peat rivers & 0.79 & 9.2 \\
Alluvial rivers & 0.03 & 6.4
\end{tabular}

$\gamma_{1}$ is the skewness parameter. $\gamma_{2}$ is the kurtosis parameter.
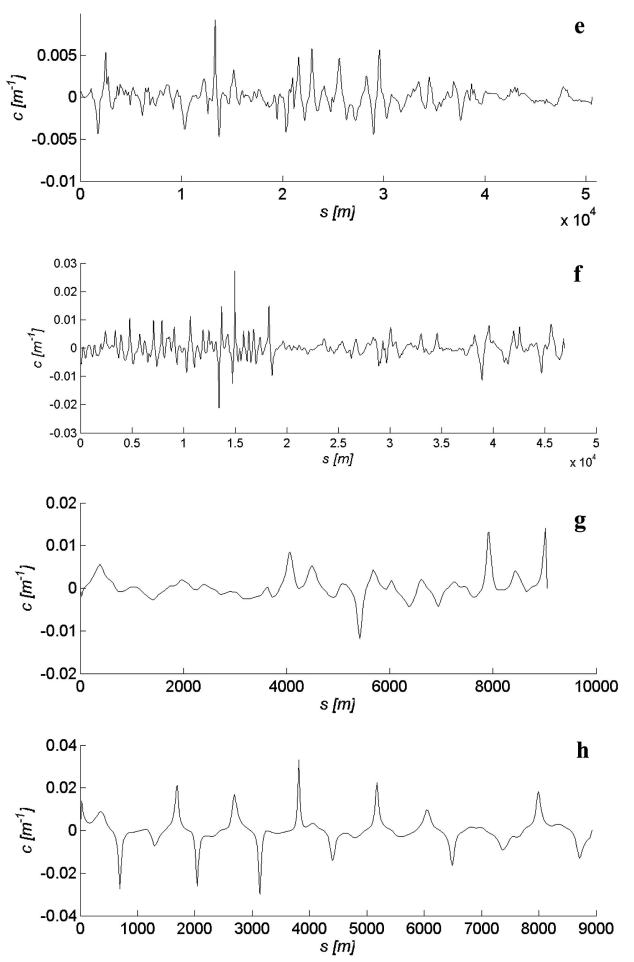

Figure 6. The curvature $c$ along the channel axis $s$, for the alluvial river reaches Kapuas (a), Air Hitam Laut reach ii (b), Air Hitam Laut reach vi (c), Air Hitam Laut reach v (d) and Air Hitam Laut reach iii (h) and the peat river reaches Mantangai (e), Air Hitam Laut reach i (f) and Air Hitam Laut reach iv (g). 
strongly curved half-meanders occurring throughout the long, almost straight half-meanders.

\section{DISCUSSION}

The planform differences of the peat and alluvial rivers that are quantified by the curvature statistics and the sinuosity parameters are likely caused by the different patterns of the valley axes, and the large differences in bank erodability. Low-frequent meandering is a direct consequence of the local geomorphology. The peat domes force the peat rivers to a path that is mainly curved to one side, giving the curvature series a high skewness. The valley axes of the alluvial reaches are less distinctly curved, resulting in lower curvature skewness. Alluvium allows for gradual adaptations of the bed morphology, whereas peat erosion occurs in during discrete events.

The sinuosity differences result from the combination of half-meander curvature and valley axis curving. The valley axes of the peat rivers are stronger curved than those of the alluvial rivers. However, since their individual half-meanders are limited in their curvature development, presumably due to the vegetation, the total sinuosity is also lower for peat rivers.

The determination of the frequencies $R_{m}$ and $R_{T}$, quantifying the distribution of small and large halfmeanders, was too subjective to be reliable. The proposed length classes were not applicable to the rivers under study. Adopting 60 adjusted length classes (custom defined for every river trajectory) did not yield satisfying results. The subsequent selection of classes for small and large half-meanders was not motivated by Howard and Hemberger (1991) and was not suitable for the rivers under study.

Regrouping the aforementioned and other variables and scaling them along the factor axes obtained by Howard \& Hemberger (1991) for a sample of natural meandering streams proved not to yield a sharper distinction between the river types than the variables individually. Furthermore, the weighing and standardizing of the variables is a subjective procedure, allowing the user to obtain different results with one set of variables. By the standardizing of the factor scores, the score differences may be enlarged, creating a unreal pattern difference.

The definition of centerline and half-meanders requires subjective decisions to be made. Though the rivers could be recognized visually from the available RADAR images, the actual tracing of the centerline suffered from the fact that river widths and river windings came close to, or were even smaller than the image resolution. The applied smoothing and interpolation routines could not effectively compensate these effects. Therefore a criterion regarding the minimal size of half-meanders was included in the programming code. Still, some excessive inflection points (creating excessive half-meanders) needed to be removed manually. Ongoing research focuses on the analysis of the curvature series of the rivers using signal-processing techniques.

\section{CONCLUSIONS}

The analysis of the geometry of individual halfmeanders quantified the differences between peat and alluvial rivers. The peat rivers are characterized by a high kurtosis and skewness of their curvature series, whereas the alluvial rivers have low values for these curvature statistics. The peat rivers feature comparatively low values of the average half-meander sinuosity, half-sinuosity, and total sinuosity parameters. The observed differences are attributed to the local geomorphology of the peat domes, forcing the peat rivers along a curved path, and the distinction between processes of bank erosion in peat and alluvium.

\section{ACKNOWLEDGEMENTS}

The contribution of H. Leijnse and M. Vissers to this research is gratefully acknowledged.

\section{REFERENCES}

Camporeale, C., P. Perona, A. Porporato, and L. Ridolfi, 2005, On the long-term behaviour of meandering rivers, Water Resour. Res., 41, W12403, doi10.1029/2005WR004109.

Hajnsek, I., F. Kugler, K. Papthanassiou, R. Scheiber, R. Horn, A. Moreira, D. Hoekman, M. Davidson and E. Attema, 2005, INDREX II - Indonesian Airborne RADAR Ecperiment Campaign over Tropical Forest in Land P-Band, Proceedings of the 2nd PolinSAR Workshop, European Space Agency, http://earth.esa.int, May 2006.

Howard, A.D., and A.T. Hemberger, 1991, Multivariate characterization of meandering, Geomorphology, 4, 161-186.

Ritzema, H., and H. Wösten, 2002, Hydrology of Borneo's Peat Swamps, STRAPEAT Status Report, Alterra, Wageningen, the Netherlands.

Savitzky, A., and M.J.E. Golay, 1964, Smoothing and Differentiation of Data by Simplified Least Squares Procedures, Analytical Chemistry, 36(8), 1627-1639.

Silvius, M.J. (ed), 2005, The Air Hitam Laut River basin; Life support functions of a black water river for people and biodiversity, Water for Food and Ecosystems Programme, Wetlands International, Wageningen, the Netherlands.

Wikramanayake, E., E. Dinerstein, C.J. Loucks, D.M. Olson, J. Morrison, J. Lamoreux, M. McKnight, and P. Hedao, 2002, Terrestrial Ecoregions of the Indo-Pacific: a conservation assessment, Island Press, Washington, USA. 
